\title{
Análise de trilha para carotenoides em milho ${ }^{1}$
}

\author{
Sara de Almeida Rios²*, Aluízio Borém³, Paulo Evaristo de Oliveira Guimarães ${ }^{4}$, Maria Cristina Dias Paes ${ }^{5}$
}

\section{RESUMO}

Ainda que sejam considerados os aspectos de magnitude e significância, o estudo de correlações entre caracteres por si só não garante causa e efeito entre eles. Dessa forma, o objetivo deste trabalho foi desdobrar as correlações fenotípicas em seus efeitos diretos e indiretos, pela análise de trilha, considerando o perfil de carotenoides em genótipos de milho. Foram utilizados dados obtidos do ensaio nacional de cultivares de milho conduzido pela Embrapa Milho e Sorgo, no ano agrícola 2004/2005, com média de 10 genótipos em cinco ambientes. Avaliaram-se os teores de carotenoides totais (CT), $\alpha$ e $\beta$-carotenos, luteína, zeaxantina e $\beta$-criptoxantina. A xantofila zeaxantina apresenta o maior efeito direto sobre $\beta$-caroteno. As altas correlações entre $\beta$-caroteno e carotenoides totais e entre $\beta$-caroteno e $\beta$-criptoxantina são devidas ao efeito indireto, via zeaxantina. A seleção direta de genótipos com altos teores de $\beta$-caroteno apresenta-se como a alternativa de maior efetividade, mas se outras frações de carotenoides também forem consideradas, esquemas de seleção simultânea de caracteres, por meio da utilização de índices de seleção, mostram-se mais eficientes na obtenção de genótipos com altos teores de $\beta$-caroteno do que a resposta correlacionada.

Palavras-chave: Zea mays L., carotenos, correlações, efeitos diretos, efeitos indiretos.

\section{ABSTRACT}

\section{Path analysis for carotenoids in maize}

Although aspects of magnitude and significance are considered, the study of correlations between traits, alone, does not necessarily guarantee a cause and effect relationship between them. Therefore, the objective of this study was to use path analysis to allow the unfolding of correlations in direct and indirect effects, considering the carotenoids profile of maize genotypes. Data was obtained from the national assay of maize cultivars conducted by Embrapa Maize and Sorghum in the 2004/2005 growing season, with means of ten genotypes in five environments. The contents of total carotenoids (CT), alpha and $\beta$-carotene, lutein, zeaxanthin and $\beta$-criptoxantin were evaluated. Xanthophyll zeaxanthin provided the highest direct effect on $\beta$-carotene. The high correlations between $\beta$-carotene and total carotenoids and between $\beta$-carotene and $\beta$-criptoxanthin are due the indirect effect via zeaxanthin. The direct selection of genotypes with high levels of $\beta$-carotene appears as a more effective alternative, but if other fractions of carotenoids were also considered, methods of simultaneous selection of characters using selection indices are more efficient in obtaining genotypes with high levels of $\beta$-carotene than the correlated response.

Key words: Zea mays L., carotenes, correlations, direct effects, indirect effects.

\footnotetext{
Recebido para publicação em 25/05/2010 e aprovado em 16/02/2012

${ }^{1}$ Parte de trabalho de tese em Genética e Melhoramento do primeiro autor.

2Engenheira-Agrônoma, Doutora. Embrapa Amazônia Ocidental, Rodovia AM-010, km 29, Zona Rural, 69010-970, Manaus, AM, Brasil. sarariosss@yahoo.com.br ("autora para correspondência).

${ }^{3}$ Engenheiro-Agrônomo, Ph.D. Departamento de Fitotecnia, Universidade Federal de Viçosa, Avenida Peter Henry Rolfs, s/n, 36570-000, Viçosa, Minas Gerais, Brasil. borem@ufv.br

${ }^{4}$ Engenheiro-Agrônomo, Doutor. Embrapa Milho e Sorgo, Caixa Postal, 285, 35701-970, Sete Lagoas, Minas Gerais, Brasil. evaristo@cnpms.embrapa.br

${ }^{5}$ Nutricionista, Ph. D. Embrapa Milho e Sorgo, Caixa Postal 285, 35701-970, Sete Lagoas, Minas Gerais, Brasil. mcdpaes@cnpms.embrapa.br
} 


\section{INTRODUÇÃO}

O conhecimento da relação linear entre caracteres nas fases iniciais de um programa de melhoramento é de grande importância, principalmente em casos em que a característica de interesse apresenta baixa herdabilidade e difícil mensuração e identificação. A utilização, portanto, de seleção indireta por resposta correlacionada pode permitir maior eficiência e progresso na seleção. Em milho, Cardoso et al. (2009) relataram altas correlações significativas entre carotenoides totais e carotenos e xantofilas. Considerando a influência das xantofilas na coloração alaranjada dos grãos de milho, poder-se-ia esperar que a seleção fenotípica com base nessa coloração fosse eficiente para obtenção de genótipos com elevados teores desses carotenoides nos grãos. Porém, Harjes et al. (2008) reportaram baixas correlações entre carotenoides totais e cor dos grãos, indicando que a seleção assistida por marcadores seria mais eficiente. No entanto, os valores de correlações, ainda que sejam considerados os aspectos de magnitude, significância e significado, não garantem uma relação de causa e efeito entre os caracteres, podendo levar a erros na sua interpretação.

A análise de trilha desenvolvida por Wright (1921) permite o desdobramento das correlações fenotípicas em efeitos diretos e indiretos dos caracteres sobre uma variável principal, o que permite maior confiabilidade na escolha dos caracteres para seleção. A mensuração dos efeitos diretos e indiretos é dependente do conjunto de caracteres estudados, que normalmente é estabelecido pelo conhecimento prévio do pesquisador e de possíveis interrelações expressas em diagramas de trilha (Cruz \& Regazzi, 1997). No desdobramento de um conjunto de caracteres sobre uma variável básica faz-se necessário estimar os coeficientes de trilha obtidos por meio de equações de regressão em que as variáveis são previamente padronizadas. O conhecimento dos efeitos diretos e indiretos que uma variável principal responde pelas demais explicativas pode auxiliar na decisão sobre a utilização de resposta correlacionada ou de índices de seleção em programas de melhoramento.

Santos et al. (2005) foram os primeiros a avaliar as inter-relações entre produtos em uma via biossintética, trabalhando com a análise de trilha para carotenoides em cenoura, e concluíram que esse desdobramento, além de auxiliar na identificação de pontos da rota metabólica, que limitam o acúmulo de carotenoides, ajuda no entendimento da evolução dessa rota de biossíntese. Considerando escassas as informações dessa natureza na literatura científica para a cultura do milho, o objetivo deste trabalho foi desdobrar as correlações fenotípicas entre a fração de carotenoide de maior atividade pró-vitamínica A ( $\beta$ caroteno) e as demais frações de carotenoides, juntamente com a produtividade de grãos, nos seus efeitos diretos e indiretos, por meio da análise de trilha.

\section{MATERIAL E MÉTODOS}

Foram utilizados dados obtidos do Ensaio Nacional de Variedades de Milho conduzido pela Embrapa Milho e Sorgo, em cinco ambientes de avaliação, no ano agrícola 2004/2005 (Tabela 1). Dentre esses, três foram no município de Sete Lagoas/MG, distintos quanto à fertilidade do solo (Tabela 1), estando o primeiro ambiente caracterizado como de solo fértil; o segundo foi aquele onde se realizou adubação com altos níveis de nitrogênio (120 kg.ha-1: 20 kg no plantio e 100 kg em cobertura); e o terceiro ambiente de avaliação foi representado por solo adubado com baixos níveis de nitrogênio (20 kg.ha${ }^{1}$ no plantio). Os outros dois ambientes de avaliação estavam localizados nos municípios de Planaltina-DF e Goiânia-GO, com diferentes altitudes, 1.000 e 823 m, respectivamente (Tabela 1$)$.

A descrição dos 10 genótipos e de suas origens, além de outras características, encontra-se na Tabela 2.

As parcelas foram constituídas de duas fileiras de quatro metros, com espaçamento de $0,90 \mathrm{~m}$ entre linhas e estande final de aproximadamente 55.000 plantas por hectare.

As análises químicas foram conduzidas no Laboratório de Qualidade de Grãos e Forragens do Centro Nacional de Pesquisa de Milho e Sorgo da Embrapa, localizado em Sete Lagoas, MG, utilizando-se delineamento em blocos casualizados, com 10 genótipos de milho, em cinco ambientes de avaliação, com duas repetições.

A debulha foi feita em debulhador mecânico, moendose os grãos obtidos em micromoinho tipo ciclone MA 020 MARCONI (Piracicaba - SP), com posterior acondicionamento das amostras em frascos de vidro, tampados, lacrados com parafilme e envoltos em papel-alumínio. Esses foram armazenados à temperatura de $-20^{\circ} \mathrm{C}$ até condução das análises químicas.

As extrações foram realizadas segundo protocolo descrito por Rodriguez-Amaya \& Kimura (2004), com posterior quantificação de carotenoides totais (CT) em espectrofotômetro Cary 50 Conc UV-Visible (VARIAN - Austrália). Carotenos ( $\alpha$ e $\beta$-carotenos) e xantofilas luteína, zeaxantina e $\beta$-criptoxantina foram quantificados por cromatografia líquida de alta eficiência (CLAE) em cromatógrafo líquido Shimadzu modelo LC-10, equipado com coluna polimérica YMC C $30(5 \mu \mathrm{m}, 4,6$ x 250 mm, Waters, Milford, MA, USA), acoplado a detector de arranjo de di-iodo. $O$ gradiente de eluição foi conduzido a 0,8 $\mathrm{mL} \mathrm{min}^{-1} \mathrm{em}$ condições de gradiente linear 80:20 a 15:85 de metanol: éter metil tert-butil em 25 min, seguido por constante de 80:20 em 5 min, finalizando com 6 min de equilíbrio. A temperatura do laboratório foi mantida a 22 ${ }^{\circ} \mathrm{C}$ durante todo o processo. Para identificação dos compostos foram utilizados padrões purificados a partir de cenoura e milho verde, seguindo protocolo descrito em Rodriguez-Amaya \& Kimura (2004). Os resultados foram 
expressos em base seca, por meio da análise de umidade realizada nas amostras, em duplicata, seguindo o método 44-15A da AACC (2000).

Foram estimados os coeficientes de correlações fenotípicas, genotípicas e ambientais entre as variáveis, utilizando-se os 10 genótipos e a média dos cinco ambientais. A análise de trilha foi realizada após o diagnóstico de multicolinearidade na matriz de correlações fenotípicas. As análises estatísticas foram realizadas por meio do software Genes, Cruz (1998).

\section{RESULTADOS E DISCUSSÃO}

A matriz de correlações fenotípicas, genotípicas e ambientes para as variáveis CT, luteína, zeaxantina, $\beta$ criptoxantina, $\beta$-caroteno, em $\mu$ g.g ${ }^{-1}$ e produtividade de grãos em kg.ha-1 está apresentada na Tabela 3, obtida das médias dos 10 genótipos de milho avaliados nos cinco ambientes.

Em geral, observaram-se correlações fenotípicas e genotípicas com mesmo sinal e magnitudes semelhantes, sugerindo confiabilidade em se utilizarem as correlações fenotípicas para interpretação dos dados, uma vez que o efeito ambiental não foi muito pronunciado (Tabela 3).

Correlações fenotípicas positivas e significativas foram observadas entre CT e as variáveis zeaxantina $(0,75)$, $\beta$-criptoxantina $(0,81)$ e $\beta$-caroteno $(0,73)$ para os genótipos estudados (Tabela 3 ). Esses resultados apontam aspectos positivos na seleção de genótipos de milho para biofortificação, principalmente considerando que os carotenoides de maior interesse são aqueles com ativida- de pró-vitamínica A ( $\beta$-caroteno; $\alpha$-caroteno; e $\beta$ criptoxantina); ou seja, poder-se-ia realizar a seleção indireta desse carotenoide por resposta correlacionada. A seleção dos genótipos apenas com base nos teores de CT significaria maior rapidez no screening dos materiais e economia de reagentes se as correlações simples entre essas variáveis apresentassem uma relação de causa e efeito.

Já os resultados de correlações fenotípicas entre luteína e os carotenoides zeaxantina e $\alpha$-caroteno foram negativos e significativos e, ainda, a correlação ambiental entre luteína e $\beta$-criptoxantina foi negativa (Tabela 3). Porém, o que se dispõe na literatura científica sobre correlações envolvendo a xantofila luteína são os resultados contraditórios (Menkir et al. 2008; Chander et al., 2008a; Chander et al., 2008b), talvez por diferenças na precisão da coleta dos dados, do tipo de população/genótipos e da interação genótipo x ambiente, além de outros motivos desconhecidos, dificultando a interpretação dessas correlações.

As correlações fenotípicas positivas e significativas entre a xantofila zeaxantina e os carotenoides precursores de vitamina A, $\beta$-criptoxantina $(0,88), \alpha$-caroteno $(0,67)$ e $\beta$-caroteno $(0,86)$ sugerem que os materiais biofortificados, além de conter altos teores de carotenoides precursores de vitamina $\mathrm{A}$, poderão ser fonte de carotenoides importantes para a qualidade da visão humana, podendo contribuir para a prevenção da degeneração macular (Tabela 3). Além disso, esses materiais teriam valor agregado como alimento para aves, principalmente poedeiras, que requerem grãos com altos teores de luteína e zeaxantina para

Tabela 1. Fertilidade dos solos para quatro dos cinco ambientes de avaliação caracterizados como Fértil, Alto N (120 kg.ha-1 $)$, Baixo N (20 kg.ha-1) e Planaltina

\begin{tabular}{|c|c|c|c|c|c|c|c|c|c|c|c|c|}
\hline \multirow{2}{*}{ Local } & \multirow{2}{*}{ Ambiente } & \multirow{2}{*}{$\frac{\mathrm{pH}}{\text { (água) }}$} & \multirow{2}{*}{$\frac{\text { MO }}{\mathrm{dag} / \mathrm{kg}}$} & $\mathbf{P}$ & $\mathbf{K}$ & Ca & Mg & $\mathbf{H}+\mathbf{A l}$ & $\mathbf{C u}$ & Zn & $\mathbf{F e}$ & Mn \\
\hline & & & & \multicolumn{2}{|c|}{$\mathrm{mg} / \mathrm{dm}^{3}$} & \multicolumn{3}{|c|}{$\mathrm{cmolc} / \mathrm{dm}^{3}$} & \multicolumn{4}{|c|}{$\mathrm{mg} / \mathrm{dm}^{3}$} \\
\hline \multirow{3}{*}{ Sete Lagoas/MG } & Fértil & 5,8 & 2,1 & 6,7 & 120 & 2,88 & 1,07 & 5,06 & 2,1 & 4,8 & 41 & 62 \\
\hline & Alto $\mathrm{N}$ & 6,1 & 3,75 & 10 & 126 & 4,62 & 0,87 & 4,39 & 1 & 3,87 & 45,2 & 25,2 \\
\hline & Baixo N & 6,2 & 3,47 & 8 & 110 & 4,18 & 0,84 & 4,05 & 2,97 & 4,5 & 46,1 & 25,1 \\
\hline Planaltina/DF & & 5,5 & 3,2 & 12,5 & 85 & 2,4 & 0,5 & 4,02 & - & - & - & - \\
\hline
\end{tabular}

Tabela 2. Caracterização dos genótipos de milho quanto à procedência, ao tipo de grão e à população

\begin{tabular}{lccc}
\hline Genótipos & Procedência & Tipo e coloração dos grãos & População \\
\hline BRS 2020 & Embrapa & Semiduro/alaranjado & Híbrido Duplo \\
Fundacep 35 & Fundacep & Semiduro/amarelo-alaranjado & Variedade \\
CMS 104 & Embrapa & Semidentado/amarelo & População \\
BRS Caatingueiro & Embrapa & Semiduro/amarelo & Variedade \\
BRS 473 cIII & Embrapa & Semiduro/amarelo-alaranjado & Variedade \\
UFVM100 & UFV & Dentado/amarelo-alaranjado & Variedade \\
CMS 102 & Embrapa & Semidentado/amarelo & População \\
CMS 101 & Embrapa & Semidentado/amarelo & População \\
BRS Missões & Embrapa & Dentado/amarelo & Variedade \\
BRS São Francisco & Embrapa & Semidentado/amarelo-alaranjado & Variedade \\
\hline
\end{tabular}

Rev. Ceres, Viçosa, v. 59, n.3, p. 368-373, mai/jun, 2012 
garantir a coloração amarelo-alaranjada das gemas dos ovos (Handelman et al., 1999).

Em geral, foram observadas baixas correlações entre produtividade de grãos e as demais frações de carotenoides (Tabela 3). Algumas correlações foram baixas e positivas (entre produtividade de grãos e as frações luteína, $\alpha$-caroteno e $\beta$-caroteno) e outras baixas e negativas (entre produtividade de grãos e as frações CT, zeaxantina e $\beta$-criptoxantina). No entanto, para nenhuma dessas correlações fenotípicas verificou-se significância pelo teste t a 1 e $5 \%$ de probabilidade. Esses resultados estão de acordo com aqueles obtidos por Menkir \& Maziya-Dixon (2004), por não haver alta correlação negativa e significativa entre produtividade de grãos e frações carotenoides; ou seja, por não se caracterizar possível ligação gênica, as correlações observadas não dificultam a obtenção de genótipos com altos teores de carotenoides e produtivos simultaneamente.

Os caracteres de maior contribuição para elevar os teores de $\beta$-caroteno, com base no estudo de correlações simples, são CT, zeaxantina e $\beta$-criptoxantina (Tabela 3).

O diagnóstico de multicolinearidade revelou que das 21 correlações analisadas, quatro apresentaram valor absoluto maior que 0,80 e quatro números de fatores de inflação da variância (VIF) superiores a 10 (Tabela 4) e número de condição (NF) maior do que 1.000, caracterizando existência de colinearidade severa. Esse resultado não inviabiliza a realização da análise de trilha, uma vez que já existem metodologias apropriadas para estudo de efeitos diretos e indiretos sob multicolinearidade (Carvalho, 1995; Carvalho et al., 1999; Coimbra et al., 2005). Logo, utilizouse a metodologia proposta por Carvalho (1995), denominada análise de trilha em crista, para estimação dos parâmetros como forma alternativa à metodologia dos quadrados mínimos. A constante $\mathrm{k}$ adicionada à diagonal da matriz X’X foi determinada pelo exame do traço da crista, por meio da construção de um gráfico onde foram plotados os coeficientes de trilha em razão dos valores de $\mathrm{k}$ no intervalo de $0<\mathrm{k}<1$.

O resultado da análise de trilha de $\beta$-caroteno em razão das variáveis explicativas CT, luteína, zeaxantina, $\beta$ criptoxantina, $\alpha$-caroteno e produtividade está apresentado na Tabela 4, com valor de $\mathrm{k}$ de 0,0497 . O coeficiente de determinação do modelo de análise de trilha $\left(\mathrm{R}^{2}\right)$ foi igual a 0,8364, caracterizando que 83,64\% da variação da variável dependente $\beta$-caroteno no modelo está sendo explicada pelas variáveis utilizadas no diagrama causal.

Apesar de o estudo de correlações simples ter apontado como caracteres de maior contribuição para elevar os teores de $\beta$-caroteno as variáveis CT, zexantina e âcriptoxantina (Tabela 3), a existência de alta correlação entre $\beta$-caroteno e as variáveis CT $(0,73)$ e $\beta$-criptoxantina $(0,88)$ não significa relação de causa e efeito entre essas variáveis; ou seja, a seleção de genótipos com altos teores de $\beta$-caroteno por resposta indireta por CT, por exemplo, não seria eficiente, considerando que a zeaxantina é que tem efeito direto elevado sobre $\beta$ caroteno (Tabela 4).

Tabela 3. Matriz de correlações fenotípicas (rfe), genéticas (rge) e ambientes (ra) entre as variáveis carotenoides totais (CT), luteína (Lut), zeaxantina (Zeax), $\beta$-criptoxantina (Bcrip), $\alpha$-caroteno (Acar), $\beta$-caroteno (Bcar), expressos em mg. g $^{-1}$ e produtividade de grãos (Prod) em kg.ha-1 obtida de 10 genótipos de milho avaliados com base na média de cinco ambientes

\begin{tabular}{|c|c|c|c|c|c|c|c|}
\hline & & Lut & Zeax & Bcrip & Acar & Bcar & Prod \\
\hline & rfe & $-0,2968$ & 0,7553* & $0,8108^{* *}$ & 0,2773 & 0,7311* & $-0,1298$ \\
\hline \multirow[t]{3}{*}{$\mathrm{CT}$} & rge & $-0,3017$ & 0,7571 & 0,8205 & 0,2840 & 0,7351 & $-0,1343$ \\
\hline & ra & 0,1604 & 0,6363 & 0,1163 & 0,1846 & 0,4810 & $-0,0711$ \\
\hline & rfe & 1 & $-0,7622 *$ & $-0,4162$ & $-0,6667 *$ & $-0,4009$ & 0,2279 \\
\hline \multirow[t]{3}{*}{ Lut } & rge & & $-0,7684$ & $-0,4149$ & $-0,6831$ & $-0,4037$ & 0,2459 \\
\hline & ra & & 0,0068 & $-0,5952$ & $-0,3858$ & $-0,1519$ & $-0,2558$ \\
\hline & rfe & & 1 & $0,8782^{* *}$ & 0,6669* & $0,8555^{* *}$ & $-0,2102$ \\
\hline \multirow[t]{3}{*}{ Zeax } & rge & & & 0,8839 & 0,6936 & 0,8594 & $-0,2100$ \\
\hline & ra & & & 0,3585 & 0,0789 & 0,5547 & $-0,3614$ \\
\hline & rfe & & & 1 & 0,5825 & $0,8778 * *$ & $-0,0602$ \\
\hline \multirow[t]{3}{*}{ Bcrip } & rge & & & & 0,6054 & 0,8816 & $-0,0662$ \\
\hline & $\mathrm{ra}$ & & & & 0,0000 & 0,6078 & 0,0806 \\
\hline & rfe & & & & 1 & 0,5631 & 0,2143 \\
\hline \multirow[t]{3}{*}{ Acar } & rge & & & & & 0,5863 & 0,2219 \\
\hline & ra & & & & & 0,0000 & 0,1249 \\
\hline & rfe & & & & & 1 & 0,0313 \\
\hline \multirow[t]{2}{*}{ Bcar } & rge & & & & & & 0,0497 \\
\hline & ra & & & & & & $-0,4312$ \\
\hline
\end{tabular}

**,*: Significativo a 1 e $5 \%$ de probabilidade, pelo teste t (para rfe). 
Tabela 4. Estimativas dos efeitos diretos e indiretos envolvendo a variável principal dependente $\beta$-caroteno e as independentes explicativas carotenoides totais, luteína, zeaxantina, $\beta$ criptoxantina, $\alpha$-caroteno e produtividade sob multicolinearidade

\begin{tabular}{|c|c|c|}
\hline Carotenoides Totais & Estimativa & VIF \\
\hline Efeito direto sobre $\beta$-caroteno & $-0,0132$ & 3,5128 \\
\hline Efeito indireto via luteína & $-0,1011$ & 0,3406 \\
\hline Efeito indireto via zeaxantina & 0,6660 & 5,7796 \\
\hline Efeito indireto via $\beta$-criptoxantina & 0,1873 & 3,7334 \\
\hline Efeito indireto via $\alpha$-caroteno & 0,0105 & 0,2257 \\
\hline Efeito indireto via produtividade & $-0,0177$ & 0,0229 \\
\hline Correlação fenotípica total & $0,7311^{*}$ & \\
\hline \multicolumn{3}{|l|}{ Luteína } \\
\hline Efeito direto sobre $\beta$-caroteno & 0,3406 & 4,2596 \\
\hline Efeito indireto via carotenoides totais & 0,0039 & 0,2809 \\
\hline Efeito indireto via zeaxantina & $-0,6721$ & 5,8850 \\
\hline Efeito indireto via $\beta$-criptoxantina & $-0,0962$ & 0,9836 \\
\hline Efeito indireto via $\alpha$-caroteno & $-0,0252$ & 1,2929 \\
\hline Efeito indireto via produtividade & 0,0310 & 0,0708 \\
\hline Correlação fenotípica total & $-0,4009$ & \\
\hline \multicolumn{3}{|l|}{ Zeaxantina } \\
\hline Efeito direto sobre $\beta$-caroteno & 0,8818 & 11,1635 \\
\hline Efeito indireto via carotenoides totais & $-0,0100$ & 1,8187 \\
\hline Efeito indireto via luteína & $-0,2596$ & 2,2455 \\
\hline Efeito indireto via $\beta$-criptoxantina & 0,2029 & 4,3797 \\
\hline Efeito indireto via $\alpha$-caroteno & 0,0253 & 1,3054 \\
\hline Efeito indireto via produtividade & $-0,0286$ & 0,0603 \\
\hline Correlação fenotípica total & $0,8555 * *$ & \\
\hline \multicolumn{3}{|l|}{ Â-Criptoxantina } \\
\hline Efeito direto sobre $\beta$-caroteno & 0,2310 & 6,2580 \\
\hline Efeito indireto via carotenoides totais & $-0,0107$ & 2,0957 \\
\hline Efeito indireto via luteína & $-0,1418$ & 0,6695 \\
\hline Efeito indireto via zeaxantina & 0,7744 & 7,8129 \\
\hline Efeito indireto via $\alpha$-caroteno & 0,0220 & 0,9869 \\
\hline Efeito indireto via produtividade & $-0,0082$ & 0,0049 \\
\hline Correlação fenotípica total & $0,8778 * *$ & \\
\hline \multicolumn{3}{|l|}{$\alpha$ - Caroteno } \\
\hline Efeito direto sobre $\beta$-caroteno & 0,0377 & 3,2052 \\
\hline Efeito indireto via carotenoides totais & $-0,0037$ & 0,2474 \\
\hline Efeito indireto via luteína & $-0,2271$ & 1,7182 \\
\hline Efeito indireto via zeaxantina & 0,5907 & 4,5467 \\
\hline Efeito indireto via $\beta$-criptoxantina & 0,1346 & 1,9269 \\
\hline Efeito indireto via produtividade & 0,0292 & 0,0626 \\
\hline Correlação fenotípica total & 0,5631 & \\
\hline \multicolumn{3}{|l|}{ Produtividade } \\
\hline $\begin{array}{l}\text { Efeito direto sobre } \beta \text {-caroteno } \\
\text { - }\end{array}$ & 0,1362 & 1,5036 \\
\hline Efeito indireto via carotenoides totais & 0,0017 & 0,0536 \\
\hline Efeito indireto via luteína & 0,0776 & 0,2006 \\
\hline Efeito indireto via zeaxantina & $-0,1854$ & 0,4478 \\
\hline Efeito indireto via $\beta$-criptoxantina & $-0,0139$ & 0,0204 \\
\hline Efeito indireto via $\alpha$-caroteno & 0,0081 & 0,1335 \\
\hline Correlação fenotípica total & 0,0313 & \\
\hline Coeficiente de determinação & & 0,8364 \\
\hline Valor de k usado na análise & & 0,0497 \\
\hline Efeito da variável residual & & 0,4044 \\
\hline
\end{tabular}

** e *: Significativos a 1 e $5 \%$ de probabilidade, pelo teste t; e VIF $=$ fator de inflação da variância.
A variável que apresentou o maior efeito direto sobre $\beta$-caroteno foi a zeaxantina $(0,88)$, e a correlação simples entre essas variáveis também foi elevada $(0,85)$, o que caracteriza efeito pronunciado da zeaxantina sobre o teor de $\beta$-caroteno (Tabela 4). Esse resultado já era esperado, uma vez que pela rota de biossíntese de carotenoides a zeaxantina é o produto da hidroxilação do $\beta$-caroteno (Howitt \& Pogson, 2006). Confirma-se, portanto, a necessidade de se realizar a varredura de genótipos promissores quanto ao teor de $\beta$-caroteno por meio da análise das frações de carotenoides, pois só a análise de CT não é suficiente, já que os resultados das correlações e posteriores desdobramentos não foram favoráveis à resposta correlacionada. Logo, a utilização de seleção direta para maiores teores $\beta$-caroteno seria vantajosa e segura, porém a seleção simultânea de caracteres por meio de índices de seleção apropriados também seria uma estratégia interessante.

\section{CONCLUSÕES}

Apenas a variável zeaxantina apresenta alta correlação e alto efeito direto sobre $\beta$-caroteno.

O screening de genótipos promissores quanto ao teor de $\beta$-caroteno deve levar em conta todas as demais frações de carotenoides, pois só a análise de CT não é suficiente para discriminar os melhores genótipos.

A seleção de genótipos com altos teores de $\beta$-caroteno pode ser realizada por meio de seleção direta ou pela utilização de índices de seleção apropriados, já que também é vantajosa a seleção de genótipos ricos em outras frações de carotenoides e de alta produtividade de grãos.

\section{REFERÊNCIAS}

AACC - American Association of Cereal Chemists (2000) Approved Methods, $10^{\mathrm{a}}$ ed. St. Paul, AACC. 1200p.

Cardoso WS, Paes MCD, Galvão JCC, Rios AS, Guimarães PEO, Schaffert RE \& Borém A (2009) Variabilidade de genótipos de milho quanto à composição de carotenoides nos grãos. Pesquisa Agropecuária Brasileira, 44:164-173.

Carvalho CGP de, Oliveira VR, Cruz CD \& Casali VWD (1999) Análise de trilha sob multicolinearidade em pimentão. Pesquisa Agropecuária Brasileira, 34:603-613.

Carvalho SP de (1995) Métodos alternativos de estimação de coeficientes de trilha e índices de seleção, sob multicolinearidade. Viçosa, UFV. 163p.

Chander S, Guo YQ, Yang XH, Zhang J, Lu XQ, Yan JB, Song TM, Rocheford TR \& Li JS (2008a) Using molecular markers to identify two major loci controlling carotenoid contents in maize grain. Theoretical and Applied Genetics, 116:223-233.

Chander S, Meng Y, Zhang Y, Yan J \& Li J (2008b) Comparison of Nutritional Traits Variability in Selected Eighty-Seven Inbreds from Chinese Maize (Zea mays L.) Germplasm. Jornal of Agricultural and Food Chemistry, 56:506-6511.

Rev. Ceres, Viçosa, v. 59, n.3, p. 368-373, mai/jun, 2012 
Coimbra JLM, Benin G, Vieira EA, Oliveira AC de, Carvalho FIF, Guidolin AF \& Soares AP (2005) Consequências da multicolinearidade sobre a análise de trilha em canola. Ciência Rural, 35:347-352.

Cruz CD (1998) Genes - Software for experimental statistics in genetics. Genetics and Molecular Biology, 21:135-138.

Cruz CD \& Regazzi AJ (1997) Modelos Biométricos Aplicados ao Melhoramento Genético. Viçosa, UFV. 390p.

Handelman GJ, Nightingale ZD, Lichtenstein AH, Schaefer EJ \& Blumberg JB (1999) Lutein and zeaxanthin concentrations in plasma after dietary supplementation with egg yolk. American Journal of Clinical Nutrition, 70:247-251.

Harjes CE, Rocheford TR, Bai L, Brutnell TP, Kandianis CB, Sowinski SG, Stapleton AE, Vallabhaneni R, Williams M, Wurtzel ET, Yan J \& Buckler ES (2008) Natural genetic variation in lycopene epsilon cyclase tapped for maize biofortification. Science, 319:330-333.

Howitt CA \& Pogson BJ (2006) Carotenoid accumulation and function in seeds and non-green tissues. Plant, Cell and Environment, 29:435-445.
Menkir A, Liu W, White W, Maziya-Dixon B \& Rocheford T (2008) Carotenoid diversity in tropicaladapted yellow maize inbred lines. Food Chemistry, 109:521-529.

Menkir A \& Maziya-Dixon B (2004) Influence of genotype and environment on $\beta$-carotene content of tropical yellowendosperm maize genotypes. Maydica, 49:313-318.

Rodriguez-Amaya DB \& Kimura M (2004) HarvestPlus Handbook for Carotenoid Analysis. Washington, DC and Cali: IFPRI and CIAT, 58p. (HarvestPlus Technical Monograph. Disponível em: <http://www.harvestplus.org/sites/default/files/tech02.pdf >. Acessado em: 13 de abril de 2007.

Santos CAF, Senalik D \& Simon PW (2005) Path analysis suggests phytoene accumulation is the key step limiting the carotenoid pathway in white carrot roots. Genetics and Molecular Biology, 28:287-293.

Wright S (1921) Correlation and causation. Journal of Agricultural Research, 20:557-585. 